\title{
Language Form in Terms of Sign Language
}

\author{
Teuta Ramadani Rasimi \\ Assistant professor \\ University of Tetova, Faculty of Education \\ Republic of North Macedonia \\ Str. Ilindenska no nr. Tetova \\ Buniamin Memedi \\ Full Professor \\ University of Tetova, Faculty of Education \\ Republic of North Macedonia \\ Str. Ilindenska no nr. Tetova \\ Arita Agai \\ Associate Professor \\ University of Tetova, Faculty of Education \\ Republic of North Macedonia \\ Str. Ilindenska no nr. Tetova
}

\begin{abstract}
Each component of language form, as a part of language structure has been an interest of discussion for decades among linguists, and hence sign language has been recognized as an autonomous real language in some countries, as special educators that teach the subjects of sign language among Albanian students, we were triggered to do to a research, by consulting different literature reviews in order to make comparison with Albanian and Kosovian sign language in terms of phonology, morphology and syntax. The objective was to analyze if there is a significant gap of difference between the spoken and signed language. The results show that each part of language form of spoken and written Albanian language can be analyzed in terms of Albanian and Kosovian signed language, which indicates the possibilities for further improvement of signed languages to become a standardized language in the future.
\end{abstract}

Keywords: sign language, language form, Albanian language

\section{Introduction}

Language, the hallmark of humanity, can be defined as an organized system of arbitrary signals and rule-governed structures that are used as a means for communication (Brandone, Salkind, Golinkoff, \& Pasek, 2006). The speaker of a certain language must have the ability to create and use signs, that is, a symbolic affiliation which includes and accepts the rules for the use of the characters. It is historically seen as the first landmark that has accompanied the human being from his birth. As such, it is very dynamic, even though the words are static, but the meaning of the words is dynamic and has level. Even though language is known to be a natural part of everyday communication between human beings as a result of their need, it can be considered also as non-instinctive, because a child has to learn the language of his society (Sapir, 1921). It is also known as arbitrary, because as Sapir (1921) said language is not inherited, the relation between the word and its meaning is learned, and this arbitrariness leads to a variety of languages, which develop the human brain, because there is no inherent reason to call an object "table" (English) or "tavolina" (Albanian). This is what makes all the languages equally complex, capable of expressing a wide range of ideas, and expandable to include a new word for new concepts. Language consists of three major components: form, content and use (Bloom \& Lahey, 1978). The first component refers to the linguistic elements that connect sounds and symbols with a meaning (Scheetz, 2012), and it includes: phonology, morphology and syntax. The second component, the content refers to the component of the language that provides us with information about objects, events, people and the relationships among them known as semantics (Scheetz, 2012), and it depends on how one's own language community labels word content in the world (Brandone, Salkind, Golinkoff, \& Pasek, 2006). 
The third component dictates how language is used in a variety of social contexts, or pragmatics. However, in this paper we analysed each component of language form in comparison to sign language.

\section{Research Methodology}

The goal of this literature review comparison was to detected and analyze each fragment of three components of language form in comparison with Albanian language, and with sign language, starting with American sign language as standardized language, and continuing with Albanian and Kosovian sign languages, that are not standardized language. By comparing each grammatical part of phonology of spoken and signed language, we discussed about similarities of the process, differences and the gap between the analyses, and the same frame for comparison was used for the second and third component of language form, morphology and syntax.

\section{Phonology}

Phonology, morphology and syntax are the units of a language that connect symbols to a meaning, regardless whether they are iconically represented or by sound (Bloom \& Lahey, 1978). Each of these units have a different role in language functioning, however their importance is evident only when they are in correlation with each other. Starting with phonology, a part of a language that is defined as historical study of sounds, or the study of the functioning of sounds in a particular language (de Saussure, 1959), enables to distinguish the difference between languages, hence every language differs by the numbers of phonemes, sounds and rules. However, linguists have distinguished phonetics from phonology, starting with Trubetzkoy(1969), who underlines phonetics as a science of speech, while phonology is considered to be dedicated to language, which in parallel is compatible with de Saussure's view (1959), who puts parole as part of phonetics, while langue as part of phonology. There has been a long dispute over their resemblance and differences of phonetics and phonology (Foley, 1977; Fudge, 1967; Woohyeok, 2012; Hjelmlev, 1953), because of the common interest that they share in the sounds of all human languages (Woohyeok, 2012), since phonetics deals with production, transmission and reception of speech sounds, phonology encompasses selection, organization and functional classification of sounds in a particular language.

Nevertheless, their differences are not strict (Rokaj, 2005), and there is no interface between phonetics and phonology with the fully autonomous nature of them (Woohyeok, 2012), because if phonetics represents the modules how a sound is created, and phonology deals with its function, neither phonology can exist without its material side (the creation of a sound), nor phonetic would have its importance without the function of the sound (Rokaj, 2005).

In Albanian language, for instance, if we take a word like bebe, which means a baby, and it is pronounced [bébe], for phoneticians the two $b$ are not the same, because the second $b$ losses its sound with the second vowel $e$, while for phonologists this is not a matter of importance, what is important is the second $b$ not to lose its intensity and become silent, like $p$, and then the word loses its meaning. To have a clearer picture of this difference, the author Rokaj (2005), gives an example of the word bark/park, where the first one means stomach, while the second means park, and this is just an example of how a word changes its meaning but is still in Albanian language, while the next time it changes, it might not be recognizable in that language (Pribanić, 1998).

So, it is the phoneme that is the main interest of phonology, and even though it has been studied for the first time by De Saussure (1959), the linguists from the School of Prague (Trubetzkoy, 1969; Jackobson, 1962), emphasized the main features of phonemes not only from speaking perspective, but also from acoustic perspective (Robins, 1997) while it undergoes changes, that according to Bloomfield (1984) those changes are a consequence of many factors, like bilingualism, different dialects etc. According to Bernstein \&Tiegerman-Farber (2009), two rules govern phoneme use. The first one is the distributional rule, which describes how a sound can be placed in various word positions, and the second is the sequencing rule, which dictates which sounds can be used together within the same syllable, to create a morpheme, the smallest unit of a word (Valli, Lucas, Mulrooney, \& Rankin, 2000). When we refer to phonetic development of a child, the first contact of typically developing children with a sound originates in the womb (Golinkoff \& Hirsh-Pasek, 1999), which means that the growing foetus can hear a number of sounds, with low and medium frequency, prosody and rhythm generated both inside and outside mothers' abdomen, so this period they are already familiar with some of the phonology of their language (Brandone, Salkind, Golinkoff, \& Pasek, 2006). As a result of these experiences, infants at birth are already familiar with some of the phonology of their language, including its intonational patterns and prosodic contours (Brandone, Salkind, Golinkoff, \& Pasek, 2006).

So, if phonology is defined as a sound system of the language, and sign language has no sounds, the definition of Brentari(1998) for sign language phonology: "as the level of grammatical analysis where primitive structural units "without meaning" are combined to create an infinite number of meaningful utterances" sheds a light on its existence in sign language. 
However, his definition has been disputed by Edward (2012), who explains that Brentari's definition refers only to "the parts of the body and the face (where we sign), does not always give a clue to the meaning of the sign, which is true for arbitrary signs but not for ironically motivated signs where the place, the movement, the shape of the hand and the orientation sometimes indicate the meaning of the sign". Consequently, it can be said that signs are composed of minimal units such as manuals (shapes, locations, and movements of the hands), non-manuals (facial expressions, head, and body postures), and the space in front of the signer, all of which contribute to sign language phonology, morphology, syntax, and discourse (Arik, 2013). In American Sign Language, the analogues of phonemes were called "cheremes" from Greek cheir hand (cf.chiro) + -eme; coined by U.S. linguist William Stokoe (Pribanić, 1998; Crasborn, van der Hulst, \& van de Kooji, 2000), and among the first pioneers who gave the first system of notation William Stokoe in his book A dictionary ofAmerican Sign Language on linguistics principles (1965), where he presented the first attempt to describe the similarities and differences between signs and phonemes, even though later was noticed that even the use of two hands (as phonological marker) versus one hand changes the meaning of the word (Crasborn, 2011).

William Stokoe had a huge impact on developing the science on sign language by providing an example of analysis of a sign, with $t a b$ symbols (see below) that explain place of articulation, dez symbols that describe the hand configuration and sig symbols that describe the action or the movement, even though it was slightly changed by Lynn Friedmann (1977) because she thought that Stokoe's description and phonemicization were inadequate to fully explore the parameters of sign language, or Hamburg Notation System for Sign Languages which includes approximately 210 characters of symbol inventory based on handshape, orientation, location and action of the sign (Hanke, 2004). Some of the symbols were as follows:

Figure 1.Stokoe's Symbols Used for Writing the Signs of ASL

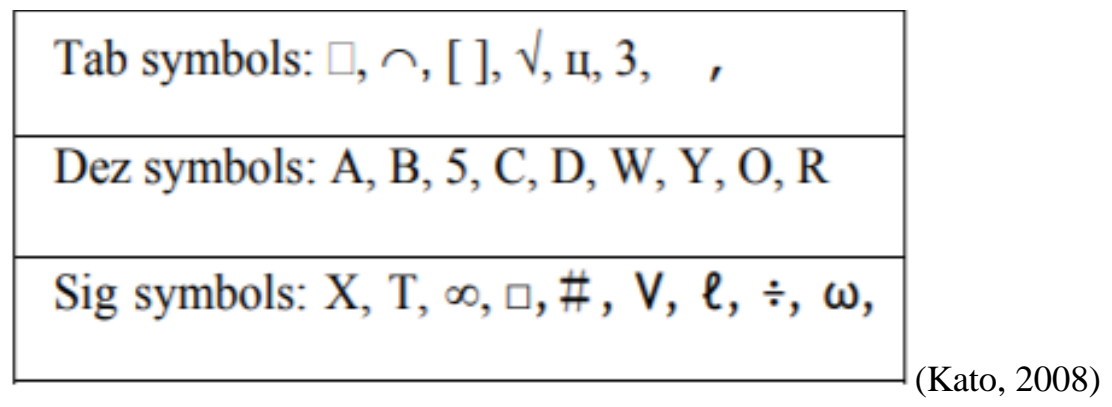

Even though this notation has been re-analyzed by other authors like Paul and Quigley (1994), new generation of authors like Mihoko Kato (2008) consider it as rather impractical for general users because they are too technical, much like phonetic alphabets in spoken languages, so different researchers have continued to analyze more specific markers, like the role play of the fingers for instance (Ormel, Crasborn, \&JannKoostra, 2017). However, like many other languages, ASL also encompasses "prosodic" elements known as intonational elements (including fascial expression and head positions) (Sandler W. 2010), and part of these elements were also analyzed by AdelinaHaskaj (2013) for Albanian Sign Language and Kosovo Sign Language, that have one thing in common, the same Albanian written and spoken standardized language. In the sample below is presented a phonological comparison between the signs according to Stokoe's notation system:

Figure 2. Comparison of some signs in KSL and ASL

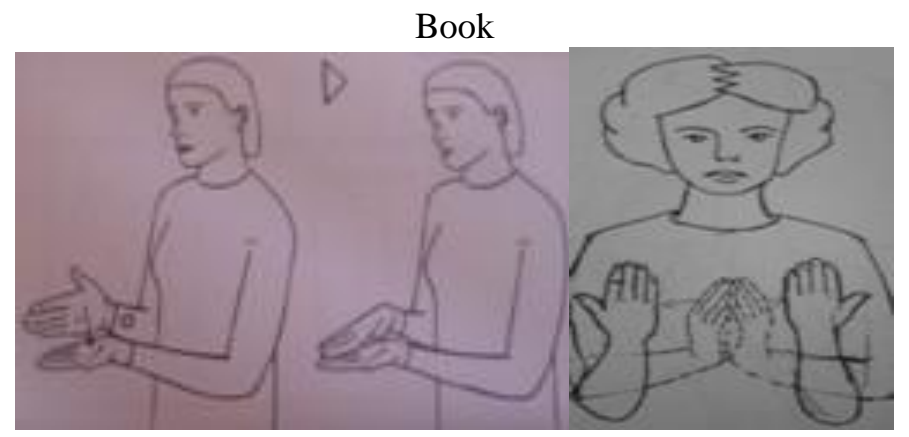


Place of articulation: in front of the stomach Hand configuration: $b$ form of the hand Movement: one hand is passive, the otheractive (Haskaj, 2013)
Place of articulation: in front of the stomach

Shape of the hand: open both hands

Movement: hands move from outside the neutral zone to inside in front of the chest (Haskaj,2013)

As can be seen by the comparison, the signed Albanian and Kosovian language, they do not undergo the similar way of phonological analysis Albanian standard spoken and written language, however it still completes the minimal standards for grammatical analysis.

\section{Morphology}

As children learn the form of the language, they spontaneously learn the rules that govern the language formation, that is morphology and syntax (Schrimer, 2000). Even though each part of the language forms is simultaneously connected to each other, it is important to emphasize the role that they play in language learning. The name itself originates from Greek, "morph" meaning "shape, form", and depending on what kind of form we are referring to, like in our case in linguistics view, then we can say that morphology as a science refers to a mental system involved in word formation, subsequently it is a branch of linguistics that deals with words, their internal structure and how they are formed (Aronoff \& Fudeman, 2011). Valli\& Lucas (2000) define morpheme as the smallest unit of a word, while morphology as a study that examines the smallest linguistic units that have meaning or grammatical function (Scheetz, 2012).

Morphemes in Albanian language, like in other languages, can consist of a word that is the root of the word (like pun, bukur), and a prefix or a suffix that cannot function alone (pun-oj, z-bukur-oj) (Rokaj, 2005; Aronoff \& Fudeman, 2011). In addition, in morphology there is a morphological analysis and synthesis, however according to linguists (Aronoff \& Fudeman, 2011), no matter which language we are looking at, we need analytic methods that will be independent of the structures we are examining; preconceived notions might interfere with an objective, scientific analysis. This is especially true when dealing with unfamiliar languages, like in the current research with Albanian and Kosovo Sign Languages, even though they are not standardized languages. In standardized languages, like American Sign Language, by using comparative morphological analysis for English and ASL, Fernald and Napoli (Fernald \& Jo Napoli, 2000) underlined the importance of sign markers as a prefix or suffix of a word, or even change the entire word, like in the case of the sign "bird" and "duck". The same rules, even though they are not scientifically studied in the Albanian Sign Language and Kosovo Sign Language can be easily traced with a simple division of two or more signs that change the meaning only by changing the location, or handshape (Toprlak \& Cakaj, 2012).

Figure 3. Examples of two signs with different meaning changed by sign markers

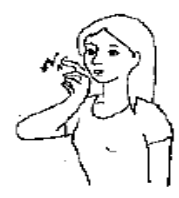

a. BIRD

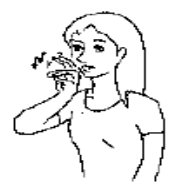

b. DUCK
(Fernald \& Jo Napoli, 2000)

So, even though sign languages can undergo the morphological analysis, we cannot see them as signed form of a spoken language, since many parts of are unrelated to spoken language, like for example Auslan (Australian Sign Language) with English. In these two languages, the concept of plural is created differently, by adding $-\mathrm{s}$ in English Language, and by repeating the movement in Auslan. (Johnston \&Schembri, 2007).

\section{Syntax}

Continuing with the third component of language form,syntax, many times correlated as morphosyntax, since it is very difficult for one to function without the other (Rokaj, 2005), and it is very closely related to the American structuralism linguists, especially of the first half of the twentieth century, because they were often dealing with languages that they had never encountered before (Aronoff\&Fudeman, 2011). The word súntaxisoriginates from Greek language, first described by Greek linguist Apollonius Dyscolus in his Per. Suntáxeōs[On Syntax], and literally means 'the act of placing together' and thus occurs in different senses, such as 'composition', 'arrangement', 'organisation', 'covenant', 'treatise' and even 'state constitution' (Sauren, 2015), and in 
Linguistic it means a system by which words are put together in any language to convey meaning. The fashionable view, in which syntax is defined as the formulation of rules to generate "acceptable" (grammatically well-formed) sentences in any language, has been disputed and dismissed by some authors (Allot, 1995), because they consider that this kind of definition undervalues the importance of meaning in languages and overvalues the grammatical form, and this separates language from its biological and psychological function (Allot, 1995). Furthermore, the structuralist was among the first (Sapir, 1921; Bloomfield, 1984) who were desperately trying to get a clear notion of syntactic facts (Sauren, 2015), and were among the first that clarified how a sentence is created, and that can be analyzed only if they split it in two parts:

"In the primary division of an experience into two parts, the one focused is called the subject and the one left for later attention the predicate; the relation between them is called predication. If, after this first division, either subject or predicate or both receive further analysis, the elements in each case first singled out are again called subjects and the elements inrelation to them, attributes. The subject is always the present thing, the known thing, or theconcrete thing, the predicate or attribute, its quality, action, or relation or the thing to whichit is like. Thus, in the sentence Lean horses run fast the subject is lean horses and the horses 'action, run fast, is the predicate. Within the subject there is the further analysis into the subject horses and its attribute lean, expressing the horses' quality. In the predicate, fast is an attributeof the subject run." (Bloomfield, 1984)

In a similar way, Albanian linguists analyze the sentence in the Albanian language, and precisely the syntactic rules are the ones that enable to create a syntactic relation between sentence unit, which means not just putting together the words, but respecting the depending relation among them (Rokaj, 2005), by creating a synthesis of words participants with a final product, a sentence or a thought (Aronoff\&Fudeman, 2011).

Different relations such as, featured, quantitative, time, place, directional, reason, purpose, result, fully, gender-typed and other type of meaning relations exist between subjects and occasions (Aliyeva, 2014), which enable to create a meaningful thought or idea. In addition, the above-mentioned linguists and other linguists struggled to define the sentence as a grammatical concept (Sauren, 2015), starting with Bloomfield (1984) who defines the sentence as a linguistic product that has internal structure in terms of layered hierarchy of constituents, to Chomksy $(1957,2002)$ according to whom a grammatical sentence means a sentence that is intuitively "acceptable to a native speaker". Regardless of the definitions, when it comes to define how a child acquires these two parts of language, morphology and syntax, or the language form in general, it has been explained and investigated by many authors (Golinkoff\& Hirsh-Pasek, 1999; Brandone, Salkind, Golinkoff, \&Pasek, 2006; Kuhl, 2004; Maguire, et al., 2010), eventually concluding that the language form occurs when the child discovers that rule-based combinations of a word actually express more than the meaning of any of individual words.

Regarding sign language, syntax is an inevitable part of its grammar, furthermore the parameters described above from Stokoe (1965) and Friedmann (1977), based on inquiries on sign language units like handshape, movement and location (Crasborn, van der Hulst, \& van de Kooji, 2000; Brentari, 1998; Liddell \& Johnson, 1989; Crasborn, 2011), can be seen analogous to phonological features like manner and place of articulation in the sub-lexical structure of spoken language (Hall, Ferreira, \& Mayberry, 2015). A rich description of similarities of syntactic structure of sign language and spoken are shown in many investigations (Neidle, Kegl, MacLaughlin, \& Lee, 2000; Sandler \& Lillo-Martin, 2006; SultonSpence \&Woll, 1999) for hierarchical phrase

structure, constituent order, movement operations, anaphora, embedding analogues to facial marking for topics and interrogatives, spatial marking for verb agreement. Even though the researchers have found familiarities between the sound language and the sign language, the difference between them remains enormous (Hall, Ferreira, \& Mayberry, 2015), and it is related to the use of sign languages of visual space, which makes possible spatial mapping of objects and places in narrative for clarity of reference much easier than spoken language, or speed of articulation of the signs compared to the spoken word, where there is a need in slowing down the muscles activity of the body in sign language compared to the sound articulated by the vocal muscles (Swisher, 1988).

In addition, many examples can be found between ASL and English Language (Lidell, 2003), like the multiple meaning of a word in English Language for example. If indeed ASL is a signed form of English Language, then that word would be presented with just one sign in ASL, furthermore we have a sentence presented in sign language only with one sign that delivers a message, while in English language more than one word is needed to deliver the same message (Jachova\&KarovskaRistovska, 2008). It is the same situation in ALSL and KSL with the Albanian language, so we analysed the signs in picture no.1 that have multiple meanings. 
Figure 4. Example of sign with multiple meanings in ALSL

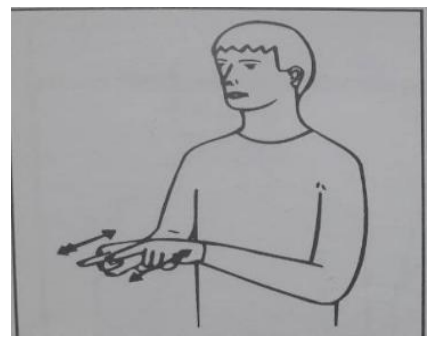

1. Brother/ sister

2. Close relative

3. Brother in law

4. Girlfriend/ boyfriend(Çabej, 2005).

The above sentence is one of the many examples that can be found in Albanian Sign Language Dictionary (Çabej, 2005), which only confirms the theories of previous authors like Zora Jachovas' and Aleksendras' (2008), that Albanian and Kosovo Sign Language is not a signed form of Albanian written and spoken language. the grammatical aspect of sign languages, despite the enormous number of investigation conducted in the area, it still remains specific in its linguistic context.

\section{Conclusion}

The grammatical aspect of sign languages, despite the enormous number of investigation conducted in the area, it still remains specific in its linguistic context. Our literature comparison shows that there is basic ground of grammatical structure of comparison between Albanian spoken and written language in terms of phonology, morphology and syntax, however signed language can be analyzed by using visual markers, which means that they differ from spoken and written Albanian language, respectively they are not signed form of Albanian language, however it is needed more in-depth improvement of each component to become a standardized sign language.

\section{References}

Aliyeva, N. (2014). A View on the Syntactical Relations. American Journal of Linguistics, 3(2), 41-45. doi:10.5923/j.linguistics.20140302.02

Allot, R. (1995). Motor theory of language in relation to syntax. In M. Landsberg (Ed.), Syntactic Iconicity and linguistic Freezes (pp. 307-329). De Gruyter Mouton. Retrieved from http://www.cogprints.org/4972/1/syntax.htm

Arik, E. (2013). Review of the book Sign Languages. Canadian Journal of Linguistics, 507-510. Retrieved from https://www.researchgate.net/publication/305073304_Review_of_the_book_Sign_languages

Aronoff, M., \&Fudeman, K. (2011). What is Morphology? Oxford, UK: Willy-Blackwell. Retrieved from http://www.ucd.ie/artspgs/introling/Aronoffmorphology.pdf

Bernstein, D., \&Tiegerman-Farber, E. (2009). Language and communication disorders in children (6th ed.). Boston: Allyn \& Bacon.

Bloom, L., \&Lahey, M. (1978). Language development and language disorders. New York: Wiley. Retrieved from https://academiccommons.columbia.edu/doi/10.7916/D8QZ2GQ5

Bloomfield, L. (1984). Language. Chicago: The University of Chicago Press. Retrieved from https://philarchive.org/archive/BLOLAO

Brandone, A., Salkind, S. J., Golinkoff, R. M., \&Pasek, K. H. (2006). LannguageDevlopment. In K. M. George G. Bear, Children's need III: Development, Prevention and Intervention (pp. 499-514). Retrieved from https://www.slideshare.net/ShahidaYasmin/bear-chapt-brandone-2

Brentari, D. (1998). A Prosodic Model of Sign Language Phonology. Massachussetts: MIT Press. Retrieved from https://epdf.tips/a-prosodic-model-of-sign-language-phonology.html

Çabej, D. (Ed.). (2005). Gjuha e shenjaveshqipe. Tirana: ILAR.

Chomsky, N. (1957, 2002). Syntactic Structure. Berlin: Walter de GruyterBmbH\& Co.

Crasborn, O. (2011). The other hand in sign language phonology. In M. Oostendorp, C. Ewen, E. Hume, \& K. Rice (Eds.), ThBlacwell Companion to Phonology (pp. 223-240). Oxford: Wiley-Blackwell. Retrieved from https://www.researchgate.net/publication/287621836_The_other_hand_in_sign_language_phonology

Crasborn, O., van der Hulst, H., \& van de Kooji, E. (2000). Phonetic and phonological distinctions in sign languages. Retrieved from http://www.sign-lang.uni-hamburg.de/intersign/internal/vdhulst2.pdf 
de Saussure, F. (1959). Course in General Lingusitics. (C. Bally, A. Sechehaye, Eds., \& W. Baskin, Trans.) New York City: The Philosophical Library, Inc.

Edward, M. (2012). THE PHONOLOGY AND MORPHOLOGY OF THE GHANAIAN SIGN LANGUAGE. Department of University of Ghana. Retrieved from https://www.researchgate.net/publication/282075082_The_Phonology_and_Morphology_of_Ghanaian_Sign_ Language

Fernald, T., \& Jo Napoli, D. (2000). Exploitation Of Morphological Possibilities In Signed Languages; Comparison of American Sign Language with English. Sign Language and Linguistics, 3-58. doi:10.1075/sll.3.1.03fer

Foley, J. (1977). Foundation of Theoretical Phonology. Cambridge: Cambridge University Press. Retrieved from http://eds.a.ebscohost.com/eds/search/basic?vid=4\&sid=30ccdea2-8c3a-4555-819b-de4c33b6d036\%40sdc-vsessmgr02

Friedman, L. (1977). Formational properties of American Sign Language. On the other hand. New York: Academic Press.

Fudge, E. (1967). The Nature of Phonological Primes. Journal of Linguistics, 1-36. doi:10.1017/S0022226700012937

Golinkoff, R., \& Hirsh-Pasek, K. (1999). How babies talk: The magic and mystery of language in the first three years of life. New York: Dutton. Retrieved from https://instantebook.club/downloads/how-babies-talk-the-magicand-mystery-of-language-in-the-first-three-years-of-life

Hall, M., Ferreira, V., \& Mayberry, R. (2015). Syntactic Priming in American Sign Language. PloS ONE, 1-19. doi:e0119611. doi:10.1371/journal.

Hanke, T. (2004). HamNoSys-Representing sign language data in language resoirces and language processing contexts. Workshop on the Representation and processing of Sign Languages. 4th International Conference on language Resources and Evaluation (pp. 1-6). Lisbon: LREC. Retrieved from https://www.researchgate.net/publication/228963927_HamNoSysRepresenting_sign_language_data_in_language_resources_and_language_processing_contexts

Haskaj, A. (2013). Differences between sign languages. Skopje: University of Ss. Cyril and Methodius.

Hjelmlev, L. (1953). Prolegomena to a Theory of Language. (F. Whitfield, Trans.) Madion: University of Wisconsin Press. Retrieved from https://www.researchgate.net/publication/244491675_Prolegomena_to_a_Theory_of_Language

Jachova, Z., \&KarovskaRistovska, A. (2008). DIFFERENCES BETWEEN AMERICAN SIGN LANGUAGE (ASL) AND BRITISH SIGN LANGUAGE (BSL). Journal of Special Education and Rehabilitation, 41-54. doi:10.5281/zenodo.28622 • Source: DOAJ

Jackobson, R. (1962). Selected Writings, 1: Phonological Studies. Hague: Mauntin\& Co. Printers. Retrieved from https://monoskop.org/images/b/b7/Jakobson_Roman_Selected_Writings_Vol_1_Phonological_Studies.pdf

Johnston , T., \&Schembri, A. (2007). Australian Sign Language (Auslan): An Introduction to Sign Language. Cambridge: Cambridge University Press. doi:10.1017/CBO9780511607479

Kato, M. (2008). A Study of Notation and Sign Writing Systems for the Deaf. Intercultural Communication Studies, 97-114. Retrieved from https://web.uri.edu/iaics/files/08-Mihoko-Kato.pdf

Kuhl, P. (2004). Early language acquisition: cracking the speech code. Nature Reviews. Neuroscience, 5(11), 831-43. doi:10.1038/nrn1533

Liddell, S., \& Johnson, R. (1989). American Sign Language.The phonological base. Sign Language Studies, 64, 197277. doi:10.1353/sls.1989.0027

Lidell, S. (2003). Grammar, Gesture, and Meaning in American Sign Language. UK: Cambridge University Press. doi:10.1017/CBO9780511615054

Maguire, M., Hirsh-Pasek, K., Golinkoff, R., Imai, M., Haryu, E., Venegas, S., \& Sanchez-Davis, B. (2010). A developmental shift from similar to language-specific strategies in verb acquisition: a comparison of English, Spanish, and Japanese. Cognition, 114(3), 299-313. doi:10.1016/j.cognition.2009.10.002

Neidle, C., Kegl, J., MacLaughlin, D., \&Lee, R. (2000). The Syntax of American Sign Language. Cambridge: MIT Press.

Ormel, E., Crasborn, O., \&JannKoostra, G. (2017, May). Coarticulation of Handshape in Sign Language of the Netherlands: A Corpus Study. Laboratory Phonology, 8(1), 1-43. Retrieved from https://www.researchgate.net/publication/316565061_Coarticulation_of_Handshape_in_Sign_Language_of_th e_Netherlands_A_Corpus_Study

Paul, P., \& Quigley, S. (1994). Language and deafness. San Diego, CA: Singular Publishin Group.

Pribanić, L. (1998). Jezicnirazvojrecenica u djeceostecenasluha. Zagreb: Edukacijsko-rehabilitacijskifakultet.

Robins, R. (1997). A Short History of Linguistics. (G. Lafe, Trans.) Tiranë: Dituria.

Rokaj, S. (2005). Hyrjenëgjuhësinë e përgjithshme. Tiranë: ShtëpiaBotuese e LibritUniverzitar. 
Sandler, W. (2010). Prosody and Syntax in Sign Languages. Transactions of the Philological Sicety, 298-328. doi:10.1111/j.1467-968X.2010.01242.x

Sandler, W., \& Lillo-Martin, D. (2006). Sign language and linguistics universals. doi:10.1017/CBO9781139163910

Sapir, E. (1921). Language, An Introduction to the study of speech. New York: Harcourt. Retrieved from http://www.ugr.es/ fmanjon/Sapir,\%20Edward\%20$\% 20$ Language, $\% 20 \mathrm{An} \% 20$ Introduction $\% 20$ to $\% 20$ the\%20Study\%20of $\% 20$ Speech.pdf

Sauren, P. (2015). Prestructuralist and Structuralist Approaches. In T. Kiss, \& A. Alexiadou (Eds.), Syntax- Theory and Analysis (pp. 134-157). Berlin: De Gruyter Mouton. Retrieved from http://pubman.mpdl.mpg.de/pubman/item/escidoc:2019230:6/component/escidoc:2441739/Seuren_2015_prest ructuralist.pdf

Scheetz, N. (2012). Deaf Education in the 21st century: Topics and Trends. New Jersey: Pearson Education, Inc.

Schrimer, B. (2000). Language and Literacy development in Children who are Deaf. Nedham Heights: Allyn \& Bacon.

Stokoe, W., Casterine, D., \&Croneberg, C. (1965). A dictionary of American Sign Language on lingustic principles. Washington D.C.: Gallaudet College Press.

Sulton-Spence, R., \&Woll, B. (1999). The linguistics of British Sign Language: An introduction. Cambridge: Cambridge Univeristy Press. Retrieved from https://www.researchgate.net/publication/318494278_The_Linguistics_of_British_Sign_Language_An_Introd uction

Swisher, V. (1988). Similarities and Differences between Spoken Languages and Natural Sign Languages. Applied Lingustics, 9(4), 343-356. doi:10.1093/applin/9.4.343

Toprlak, D., \&Cakaj, N. (Eds.). (2012). Gjuha e ShenjaveKosovare. Prishtinë: Koha Print.

Trubetzkoy, N. (1969). Principles of Phonology. (C. A. Baltaxe, Trans.) Los Angeles, California: University of California Press. Retrieved June 14, 2018, from https://monoskop.org/images/7/73/Trubetzkoy_NS_Principles_of_Phonology.pdf

Valli, C., Lucas, C., Mulrooney, K., \& Rankin, M. (2000). Linguistics of American Sign Language. Washington DC: Gallaudet University Press. Retrieved from https://www.researchgate.net/publication/246700266_Linguistics_of_American_Sign_Language

Woohyeok , C. (2012). On the Relation between Phonetics and Phonology. Linguistic Research, 29(11), 127-156. doi:10.17250/khisli.29.1.201204.006 